\title{
Gambaran Terapi Awal Pada Pasien Gerd (Gastroesophageal Reflux Disease) Di Poliklinik Penyakit Dalam Rsud Dr. Soekardjo
}

\author{
1*Asep Abdul Rahman,Widya Maulidina, Eva Dania Kosasih \\ PoltekkesKemenkesTasikmalaya, Indonesia \\ Email Korespondensi : asep8971@gmail.com
}

\begin{abstract}
Abstrak
Gastroesophageal Refluks Disease (GERD) adalah aliran balik (refluks) isi lambung secara berulang sehingga menimbulkan gejala yang mengganggu dan menurunkan kualitas hidup penderita. Penelitian ini betujuan untuk mengetahui gambaran pengobatan pasien GERD di Poliklinik Penyakit Dalam RSUD dr. Soekardjo Tasikmalaya tahun 2018. Penelitian ini merupakan penelitian deskriptif non eksperimental dengan pengambilan data secara retrospektif menggunakan metode purposive sampling dan dianalisis dengan metode analisis deskriptif terhadap 86 sampel data rekam medik pasien GERD rawat jalan yang memenuhi kriteria inklusi. Hasil penelitian menunjukan bahwa pasien GERD banyak ditemukan pada perempuan sebanyak $66,3 \%$, rata-rata berusia 41-60 tahun sebanyak 44,2\% dan 82,6\% pasien tidak memiliki riwayat penyakit berisiko. Obat GERD terbanyak diberikan adalah lansoprazol sebanyak 37,9\% dengan dosis $30 \mathrm{mg} / \mathrm{hari}$ sebanyak 37,9\%, berdasarkan aturan pakai, terapi farmakologi GERD banyak diberikan sebelum makan dan lama pemberian pada terapi awal rata-rata selama 1-14 hari sebanyak $62,6 \%$.
\end{abstract}

Kata kunci: Gastroesophageal Refluks Disease, Poliklinik Penyakit Dalam, terapi awal

\section{Initial Therapy For Gerd (Gastroesophageal Reflux Disease) Patients In Internist Departement Of Rsud Dr. Soekardjo}

\begin{abstract}
Gastroesophageal Reflux Disease (GERD) is a recurrent (reflux) of gastric contents that causes distrubing symptoms and reduce the life quality of patients. This study aims to describe the treatment of GERD patients in the Internist Polyclinic of RSUD dr. Soekardjo Tasikmalaya in 2018. This study is a descriptive non- experimental study with retrospective data collection using purposive sampling method and analyzed by descriptive analysis method on 86 samples of medical record data of outpatient GERD patients who meet the inclusion criteria. The results showed that GERD patients were found in women as many as $66.3 \%$, the average age of $41-60$ years was $44.2 \%$ and $82.6 \%$ of patients did not have a history of risky disease. Most GERD drugs given are lansoprazole as many as $\mathbf{3 7 . 9 \%}$ with a dose of 30 $\mathrm{mg} /$ day as many as 37.9\%, based on the rules of use, many pharmacological therapies GERD are given before meals and duration of administration on initial initial therapy for $1-14$ days as many as 62.6\%.
\end{abstract}

Keywords: Gastroesphageal Reflux Disease, Internist Polyclinic, initial therapy 


\section{PENDAHULUAN}

Gaya hidup seperti merokok, konsumsi alkohol, obesitas, makan terlalu banyak, kopi, stress, berbaring setelah makan, mengkonsumsi makanan atau minuman asam dapat menyebabkan gangguan kesehatan system pencernaan. Gaya hidup tersebut dapat menyebabkan gangguan kesehatan sistem pencernaan salah satunya GERD (Gastroesophageal Reflux Disease). GERD adalah gangguan berupa isi lambung mengalami refluks berulang ke dalam esofagus, menyebabkan gejala dan atau komplikasi yang mengganggu (Saputera, 2017). Gejala khas GERD adalah heartburn dan regurgitation (Karina, 2016).

Bahaya penyakit GERD jika dibiarkan terus menerus akan merusak fungsi sistem pencernaan dan meningkatkan risiko terkena kanker esofagus sehingga diperlukan pengobatan yang tepat (Ndraha, 2016).

Prevalensi GERD di Indonesia telah mencapai 27,4\% (Syam, 2016). Berdasarkan studi pendahuluan, pasien GERD di RSUD dr. Soekardjo Tasikmalaya mengalami peningkatan sebanyak $12 \%$ dari tahun sebelumnya. Hal ini kemungkinan disebabkan gaya hidup yang tidak sehat semakin meningkat, kekambuhan pasien GERD akibat pola pengobatan yang kurang tepat atau faktor risiko seperti penggunaan obat-obatan seperti teofilin, antikolinergik, beta adrenergik, nitrat dan calcium-channel blocker secara bersamaan (Saputera, 2017).

Berdasarkan permasalahan tersebut serta belum pernah dilakukan penelitian terkait pengobatan GERD, maka perlu dilakukan penelitian mengenai pola pengobatan GERD yang dipusatkan di Poliklinik Penyakit Dalam
RSUD dr. Soekardjo Tasikmalaya. Penelitian ini dilakukan untuk mengetahui bagaimana gambaran pola pengobatan GERD di RSUD dr.Soekardjo Tasikmalaya Tahun 2018.

\section{METODE}

Metode yang digunakan ralam
penelitian ini yaitu deskriptif $\begin{array}{r}\text { dengan } \\ \text { pengambilan data dilakukan secara retrospektif }\end{array}$
terhadap 86 sampel rekam medis pasien rawat
jalan Poliklinik Penyakit Dalam RSUD dr.
Soekardjo Tasikmalaya tahun 2018
menggunakan instrumen penelitian berupa
lembar pengumpulan data yang dibuat oleh
peneliti dilakukan dengan cara mencatat isi
rekam medis. Teknik analisis data yang
digunakan dalam penelitian ini adalah analisis
deskriptif kuantitatif mendeskripsikan
karakteristik setiap variabel penelitian.

\section{HASIL}

\section{Karakteristik Pasien}

Dari 86 data rekam medis yang memenuhi kriteria inklusi subjek penelitian $33,7 \%$ adalah laki-laki, $66,3 \%$ perempuan. Usia pasien terbanyak adalah $>40$ tahun. Jika ditinjau dari riwayat penyakit $17,4 \%$ memiliki penyakit yang berisiko menyebabkan GERD akibat penggunaan obat-obat terapi tersebut.

\begin{tabular}{|c|c|c|c|c|c|c|}
\hline \multirow[t]{2}{*}{ No. } & \multirow[t]{2}{*}{ Usia } & \multicolumn{2}{|c|}{$\begin{array}{c}\text { Jenis } \\
\text { Kelamin }\end{array}$} & \multirow[t]{2}{*}{ Total } & \multicolumn{2}{|c|}{$\begin{array}{l}\text { Riwayat } \\
\text { Penyakit }\end{array}$} \\
\hline & & $\mathrm{L}$ & $\mathrm{P}$ & & Ada & Tidak \\
\hline 1. & $18-40$ & 12 & 25 & 37 & 1 & 36 \\
\hline 2. & $41-60$ & 13 & 25 & 38 & 6 & 32 \\
\hline \multirow[t]{3}{*}{3.} & $>60$ & 4 & 7 & 11 & 7 & 4 \\
\hline & Jumlah & 29 & 57 & 86 & 15 & 71 \\
\hline & Persentase & 33,7 & 66,3 & & 17,4 & 82,6 \\
\hline
\end{tabular}




\section{Terapi Farmakologi}

Berdasarkan data yang diperoleh diketahui bahwa obat paling banyak diterima pasien adalah lansoprazol $30 \mathrm{mg}$ sebanyak 37,9\%, diikuti oleh sukralfat $4.500 \mathrm{mg}$ sebanyak $17,4 \%$ dan domperidon 30 mg sebanyak 17,9\%. Penggunaan obat dan kombinasi tersebut disesuaikan dengan derajat esakitan pasien.

Tabel 2. Terapi farmakologi berdasarkan zat aktif dan dosis

\begin{tabular}{ccccc}
\hline No. & Zat Aktif & Dosis/hari & $\mathbf{n}$ & $\%$ \\
\hline 1 & Cisapride & $30 \mathrm{mg}$ & 1 & 0,5 \\
\hline \multirow{2}{*}{2} & Domperidon & $15 \mathrm{mg}$ & 1 & 0,5 \\
& & $30 \mathrm{mg}$ & 34 & 17,9 \\
& & & \\
\hline \multirow{2}{*}{3} & Lansoprazol & $30 \mathrm{mg}$ & 72 & 37,9 \\
4 & Metoklopramid & $30 \mathrm{mg}$ & 1 & 0,5 \\
\hline \multirow{2}{*}{5} & \multirow{2}{*}{ Omeprazol } & $20 \mathrm{mg}$ & 12 & 6,3 \\
& & $40 \mathrm{mg}$ & 2 & 1,1 \\
\hline 6 & Ranitidin & $300 \mathrm{mg}$ & 1 & 0,5 \\
\hline 7 & Rebamipid & $300 \mathrm{mg}$ & 4 & 2,1 \\
& e & & & \\
\hline \multirow{2}{*}{8} & Sukralfat & $4.000 \mathrm{mg}$ & 27 & 14,2 \\
& & $4.500 \mathrm{mg}$ & 33 & 17,4 \\
\hline
\end{tabular}

Persentase terbanyak berdasarkan tabel 3. adalah penggunaan kombinasi obat lansoprazol yang dikonsumsi setelah makan dengan sukralfat dikonsumsi sebelum makan sebanyak 34,9\%. Aturan pakai tersebut telah disesuaikan dengan referensi. Persentase ini didapat dari jumlah sampel rekam medis. Golongan PPI merupakan obat utama dalam terapi kombinasi pasien GERD. Secara keseluruhan obatobat GERD dikonsumsi sebelum makan, namun beberapa kasus untuk terapi kombinasi disesuaikan untuk menghindari reaksi antar obat. 
Tabel 3. Terapi farmakologi berdasarkan aturan pakai

\begin{tabular}{|c|c|c|c|c|}
\hline No. & Zat Aktif & Aturan Pakai & $\mathbf{N}$ & $\%$ \\
\hline 1 & Lansoprazol & sebelum makan & 10 & 11,6 \\
\hline 2 & Lansoprazol + Cisapride & $\begin{array}{l}\text { sebelum makan }+ \text { sebelum } \\
\text { makan }\end{array}$ & 1 & 1,2 \\
\hline 3 & Lansoprazol + Domperidon & $\begin{array}{l}\text { sebelum makan + sebelum } \\
\text { makan }\end{array}$ & 7 & 8,1 \\
\hline 4 & Lansoprazol + Metoklopramid & $\begin{array}{l}\text { sebelum makan + sebelum } \\
\text { makan }\end{array}$ & 1 & 1,2 \\
\hline 5 & Lansoprazol + Rebamipid & $\begin{array}{l}\text { sebelum makan }+ \text { sebelum } \\
\text { makan }\end{array}$ & 3 & 3,5 \\
\hline
\end{tabular}

\begin{tabular}{cllcc}
\hline 6 & Lansoprazol + Sukrakfat & setelah makan + sebelum makan & 30 & 34,9 \\
\hline 7 & $\begin{array}{l}\text { Lansoprazol + Sukrakfat }+ \\
\text { Domperidon }\end{array}$ & $\begin{array}{l}\text { setelah makan + sebelum makan } \\
+ \text { sebelum makan }\end{array}$ & 16 & 18,6 \\
\hline 8 & $\begin{array}{l}\text { Lansoprazol + Sukrakfat }+ \\
\text { Ranitidin }\end{array}$ & $\begin{array}{l}\text { setelah makan + sebelum makan } \\
+ \text { setelah makan }\end{array}$ & 1 & 1,2 \\
\hline 9 & $\begin{array}{l}\text { Lansoprazol + Sukrakfat }+ \\
\text { Rebamipid }\end{array}$ & $\begin{array}{l}\text { setelah makan + sebelum makan } \\
+ \text { sebelum makan }\end{array}$ & 1 & 1,2
\end{tabular}

\begin{tabular}{lllll}
\hline 10 & Omeprazol & Sebelum makan & 1 & 1,2 \\
\hline \multirow{2}{*}{11} & Omeprazol + Domperidon & sebelum makan + sebelum & makan & 1
\end{tabular}

\begin{tabular}{lllrr}
\hline 12 & Omeprazol + Sukrakfat & setelah makan + sebelum makan & 3 & 3,5 \\
\hline 13 & $\begin{array}{l}\text { Omeprazol + Sukrakfat }+ \\
\text { Domperidon }\end{array}$ & $\begin{array}{l}\text { setelah makan + sebelum makan } \\
+ \text { sebelum makan }\end{array}$ & 11 & 12,8 \\
& & Jumlah & $\mathbf{8 6}$ & $\mathbf{1 0 0 , 0}$ \\
\hline
\end{tabular}

Penentuan lama penggunaan dilakukan dengan melihat jumlah obat yang diberikan tertulis didata rekam medis atau jangka waktu antara terapi awal pasien GERD diberikan dengan waktu kontrol selanjutnya. Lama penggunaan obat terapi awal GERD di poliklinik penyakit dalam RSUD dr. Soekardjo Tasikmalaya tahun 2018 rata-rata dilakukan selama 1-14 hari pengobatan yakni sebanyak 62,6\%. Sedangkan penggunaan obat selama 1-30 hari didapat 37,4\%.

Tabel 4. Terapi farmakologi berdasarkan lama penggunaan

\begin{tabular}{ccccc}
\hline Zat Aktif & \multicolumn{2}{c}{ Lama Penggunaan di Lapangan } & & Lama Penggunaan \\
\cline { 2 - 5 } & $1-14$ hari & $1-30$ hari & & \\
\hline Lansoprazol & 47 & 25 & 14 & $\begin{array}{c}\text { Terapi inisial: 2-4 minggu } \\
\text { On-demand : 4-8 minggu } \\
\text { Omeprazol }\end{array}$ \\
& 10 & 4 & & (Bestari, 2011) \\
\hline $\begin{array}{c}\text { Metoklopramid } \\
\text { Domperidon }\end{array}$ & - & 1 & 35 & Terapi inisial: $7-14$ hari \\
\end{tabular}


JURNAL KESEHATAN POLTEKKES KEMENKES RI PANGKALPINANG

Vol. 2, No.6, Desember 2018

P-ISSN.2339-2150, E-ISSN 2620-6234

\begin{tabular}{crrrr}
\hline Sukralfat & 41 & 21 & 62 & $2-8$ minggu (Wardaniati, 2016) \\
\hline Ranitidin & 1 & - & 1 & $2-4$ minggu (Irawati, 2013) \\
\hline Rebamipid & 3 & 1 & 4 & \\
Cisaprid & 1 & - & 1 & \\
\hline $\mathbf{n}$ & $\mathbf{1 1 9}$ & $\mathbf{7 1}$ & $\mathbf{1 9 0}$ & \\
\hline
\end{tabular}




\section{PEMBAHASAN}

Pasien perempuan lebih tinggi dibandingkan pasien laki-laki. Hal ini sejalan dengan penelitian yang dilakukan di Jepang, Miyamoto (2008) penderita GERD terbanyak adalah perempuan. Tingginya insidensi pada perempuan disebabkan karena pengaruh hormon estrogen dan progesteron. Salah satu fungsi hormon ini adalahuntuk merelaksasi otot dalam tubuh sehingga dapat menurunkan tekanan LES (Makmun, 2009). Selain itu, gaya hidup menjadi penyebab prevalensi GERD pada ibu rumah tangga lebih tinggi. Hal tersebut disebabkan ibu rumah tangga lebih sensitif terhadap perasaan dan tingkat stress lebih tinggi daripada laki-laki sehingga psikisnya terganggu, cemas, tegang dan perasaan takut berlebih memicu sekresi asam lambung tinggi (Diatsa, 2016).

Karakteristik usia pasien padapenelitian ini dibagi dalam 3 kelompok usia menurut Hurlock (1980) yaitu kelompok usia dewasa awal (18-40 tahun), dewasa akhir (41-60 tahun) dan lansia (>60 tahun). Tujuan dari pengelompokan usia ini adalah untuk mengetahui keterkaitan usia terhadap prevalensi GERD. Berdasarkan perolehan data, dapat disimpulkan bahwa pasien GERD di Poliklinik Penyakit Dalam RSUD dr. Soekardjo Tasikmalaya Tahun 2018 didominasi usia 41-60 tahun. Hasil ini sesuai dengan penelitian Karina (2015) bahwa insidensi GERD tinggi pada usia $>40$ tahun. Hal ini dikarenakan usia tersebut merupakan usia produktif sehingga berbagai kesibukan pekerjaan dan kegiatan lainnya berpotensi menimbulkan pola hidup tidak sehat dan stress yang dapat meningkatkan insiden GERD.

Pasien GERD dengan riwayat penyakit yang berisiko menjadi penyebab GERD dihasilkan lebih sedikit dibanding dengan pasien yang tidak memiliki riwayat penyakit yang berisiko GERD. Risiko tersebut disebabkan dari penggunaan obat terapi hipertensi, HHD, ISPA, CHF dan obat-obat lain penurun tonus LES (Saputera, 2017). Sedangkan yang tidak memiliki riwayat pengobatan yang menimbulkan GERD atau dengan kata lain pasien tersebut menderita
GERD karena gaya hidup tidak sehat.

Terapi farmakologi pasien GERD paling banyak menggunakan lansoprazol. Hal ini sejalan dengan penelitian sebelumnya tentang efektifitas omeprazole dan lansoprazol bahwa omeprazole memiliki bioavailabilitas lebih rendah $(35 \%-60 \%)$ daripada lansoprazol (80\%) (Achmad, 2011). Lansoprazol dan omeprazole merupakan golongan PPI dengan mekanisme kerja mengontrol sekresi asam lambung dengan menghambat pompa proton yang mentransfer ion $\mathrm{H}^{+}$keluar dari sel pariental lambung. Sukralfat menjadi obat paling banyak digunakan kedua. Sukralfat merupakan golongan sitoprotektif berperan meningkatkan sekresi prostaglandin endogen untuk meningkatkan produksi bikarbonat sehingga dapat mencegah kekambuhan (Pang, 2013). Penggunaan obat golongan sitoprotektif lain ialah rebamipid namun penggunaannya sangat sedikit. Hal ini disebabkan penggunaan rebamipid tidak mempercepat proses

kesembuhan dibandingkan terapi tunggal lansoprazol (Melinda, 2011). Domperidon menjadi peringkat ketiga setelah lansoprazol dan sukralfat. Domperidon merupakan golongan prokinetik dengan mekanisme kerja meningkatkan motilitas esofagus dan lambung sehingga membantu mempercepat waktu pengosongan lambung serta dapat meningkatkan tekanan LES dan mengurangi gejala muntah dan regurgitasi. Kelebihan domperidon daripada golongan prokinetik lain yakni domperidon memiliki efek ekstrapiramida paling ringan (Irawati, 2013).

Ranitidin menjadi obat paling sedikit digunakan dalam penelitian ini. Ranitidin merupakan golongan H2RA berperan dalam mengurangi faktor agresif dengan cara menghambat histamin pada reseptor $\mathrm{H}_{2}$ sel parietal sehingga sel parietal tidak terangsang mengeluarkan asam lambung. Namun menurut Syam (2013) dalam studinya mengatakan bahwa omeprazole masih jauh lebih efektif dibandingkan ranitidine dalam menurunkan cairan lambung sehingga penggunaannya dalam pengobatan GERD sedikit.

Berdasarkan tabel 1. diketahui bahwa dosis pemberian obat paling banyak diresepkan yaitu lansoprazol dengan dosis $30 \mathrm{mg} / \mathrm{hari}$ 74 
dalam dosis tunggal ataupun ganda, hal ini telah sesuai dengan guidelines Diagnosis dan Tatalaksana GERD. Disamping itu, omeprazole diberikan 20-40 mg/ hari dengan dosis tunggal maupun ganda juga telah sesuai standar (Saputera, 2017). Penggunaan domperidon sebagai terapi pendamping diberikan dalam dosis $30 \mathrm{mg} /$ hari setiap 8 jam. Sedangkan obat prokinetik metoklopramid dan cisapridemasingmasing diberikan $30 \mathrm{mg} /$ hari setiap 8 jam. Dosis tersebut telah sesuai dengan guidelines penggunaan obat prokinetik pada pasien GERD (Saputera, 2017).

Menurut standar IONI (2014) dosis sukralfat untuk terapi GERD diberikan 4.000 $\mathrm{mg} /$ hari setiap 6 jam, atau disesuaikan dengan petunjuk dokter. Bentuk sediaan sukralfat yang diresepkan dokter di poliklinik penyakit dalam RSUD dr. Soekardjo Tasikmalaya Tahun 2018 yaitu suspensi dengan kekuatan obat $500 \mathrm{mg} / 5$ $\mathrm{mL}$.

Berdasarkan tabel 2. sebagian besar terapi farmakologi GERD dikonsumsi sebelum makan. Hal ini karena sebagian besar obat-obat gastrointestinal memerlukan aktivasi dilingkungan asam (Eswaran, 2013). Jika dosis tunggal, semua sediaan PPI delayed release harus diberikan 30-60 menit sebelum makan. PPI efektif jika pemberian dilakukan pada malam sebelum tidur, hal ini bertujuan untuk memaksimalkan pengendalian $\mathrm{pH}$ lambung karena sekresi $\mathrm{HCl}$ meningkat malam hari. Jika pemberian dosis ganda, maka pemberian juga dilakukan pagi hari sebelum makan. Pemberian bersama dengan sukralfat akan mengurangi bioavailabilitas lansoprazole, oleh karena itu jangan diberikan kurang dari satu jam setelah minum lansoprazol (Irawati, 2013). Karena diaktivasi oleh asam, maka sukralfat digunakan pada kondisi lambung kosong, satu jam sebelum makan.

Ranitidin merupakan golongan H2RA yang baik digunakan 30-60 menit sebelum makan. Namun dalam kasus ini ranitidin boleh diberikan setelah makan. Jika dikombinasikan dengan sukralfat dapat menurunkan konsentrasi pada ranitidin. Disarankan bahwa ranitidin diberikan satu atau dua jam setelah sukralfat (Wardaniati, 2016)
Perolehan data didapat durasi pemberian obat pada pasien GERD dengan jumlah kasus terbanyak yaitu selama 1-14 hari terapi. Pemberian obat interval waktu 1-14 hari merupakan terapi awal. Jika responnya sesuai, terapi dilanjutkan sampai 4 minggu sebelum memasuki terapi on-demand (Bestari, 2011). Namun dalam penggunaan jangka panjang, obat-obat tersebut dapat meningkatkan insidensi tumor karsinoid lambung yang kemungkinan berhubungan dengan efek hiperklorhidria yang berkepanjangan dan hipergastrinemia sekunder (Burmana, 2015).

\section{KESIMPULAN}

1. Berdasarkan karakteristik pasien GERD, jenis kelamin terbanyak adalah perempuan dalam kelompok usia 41-60 tahun dan $82,6 \%$ tidak memiliki riwayat penyakit yang menyebabkan GERD.

2. Pemberian terapi farmakologi paling banyak berdasarkan zat aktif adalah lansoprazol dengan dosis $30 \mathrm{mg} /$ hari diikuti terpi pendamping domperidon $30 \mathrm{mg} /$ hari sebanyak dan sukralfat $4.500 \mathrm{mg} / \mathrm{hari}$ Berdasarkan aturan pakai, obat-obat GERD diminum sebelum makan dan disesuaikan dengan kombinasi obat lainnya agar efek terapi didapat secara optimal. Kebanyakan pasien mendapatkan terapi awal selama 114 hari.

\section{DAFTAR PUSTAKA}

Achmad, A., 2011, Effectiveness Omeprazole And Lansoprazole In Dyspepsia Patient With Nepean Dyspepsia Index, Departement of Clinical Pharmacy, Faculty of Medical and Health Sciences, University of Jenderal Soedirman, Purwokerto Folia Medica Indonesiana Vol. 47 No. 1, 15-19.

Bestari, M.B., 2011, Penatalaksanaan Gastroesophageal Reflux Disease (GERD), Continuing Medical Education Vol. 38 No. 7.

Burmana, F., 2015, Ketepatan Teknik Dan Saat Pemberian Obat Gastritis Pada Pasien Dewasa Di Puskesmas Rawat Inap Kemiling Bandar 
JURNAL KESEHATAN POLTEKKES KEMENKES RI PANGKALPINANG P-ISSN.2339-2150, E-ISSN 2620-6234

Lampung Periode 2013, Skripsi, Fakultas Kedokteran Universitas Lampung, Bandar Lampung.

Diatsa, B., 2016, Hubungan Pola Makan dengan Kejadian Gastritis pada Remaja di Pondok AlHikmah Trayon Karanggede Boyolali, Skripsi, Fakultas Ilmu Kesehatan Universitas Muhammadiyah, Surakarta.

Ekawardana, F., Andayani, R., dan Rezeki, S., 2017, Gambaran Laju Aliran Saliva Tanpa Stimulasi Pada Pasien Terindikasi Gasrtoesophageal Reflux Disease (GERD) Di Rumah Sakit Umum Daerah Zainal Abidin Banda Aceh, Journal Caninus Denstistry Vol. 2, No. 1, 7-11.

Eswaran, S., Muir, J., \& Chey, W. D., 2013, Fiber and functional gastrointestinal disorders, The American journal of gastroenterology 108(5), 718.

Hurlock, and Elizabeth, 1980, Psikologi Perkembangan: Suatu Pendekatan Sepanjang Hidup, Erlangga, Jakarta, hal 246.

Irawati, S., 2013, Penatalaksanaan Gastroesophageal Reflux Disease (GERD), Buletin Rasional Vol. 11 No. 1.

Karina, R., Fajar, A.Y., dan Astuti, R., 2016 Karakteristik Penderita Gastroesophageal Reflux Disease (GERD) Berdasarkan Usia, Jenis Kelamin dan Keluhan Utama di Poli Penyakit Dalam Rumah Sakit Al Islam Bandung2015, Prosiding Pendidikan Dokter Vol. 2 No 2.

Makmun, D., 2009, Penyakit Refluks Gastroesofagus dalam Buku Ajar Ilmu Penyakit dalam Jilid I Edisi $V$, InternaPublishing, Jakarta.

Melinda, M., 2011, Efikasi Kombinasi Rebamipide dengan Lansoprazole pada Proses Penyembuhan Tukak Lambung Tikus yang Dipapar Indometasin, Jurnal Kedokteran Brawijaya Vol. 26 No. 3

Miyamoto, M., Haruma, K, Takeuci K, and Kuwabara, M., 2008, Frequency Scale for
Vol. 2, No.6, Desember 2018

Symptoms of Gastroesophageal Reflux Disease Predicts the Need for Addition of Prokinetics to Proton Pump Inhibitor Therapy, J Gastroenterol Hepatol 23:746- 51.

Ndraha, S., Oktavius, D., et al., 2016, FaktorFaktor yang Berhubungan dengan Keberhasilan Terapi GERD, Jurnal Kedokteran Medikte Vol. 22 No. 60.

Pang, M.,R., 2013, Penatalaksanaan Gangguan Saluran Pencernaan di Rumah sakit Panti Rini Yogyakarta Periode Juli 2012 Kajian: Dosis Obat dan Kemungkinan Interaksi Obat, Skripsi, Fakultas Farmasi Universitas Sanata Dharma, Yogyakarta.

Saputera, M.D., dan Budianto, W., 2017, Diagnosis dan Tatalaksana Gastroesophageal Reflux Disease (GERD) di Pusat Pelayanan Kesehatan Primer, Jurnal Continuing Medical Education Vol. 44 No 5.

Syam, A. F., Hapsari, P. F., dan Makmun, D., 2016, The prevalence and risk factors of GERD among Indonesian medical doctors. Makara Journal of Health Research, 35-40.

Syam, H., 2013, Perbandingan Keasaman Refluxat Laringofaringeal Pasien Pasca Bedah Elektif Di Rumah Sakit Wahidin Sudirohusodo Makassar, Thesis, Fakultas Kedokteran Universitas Hasannudidin, Makasar.

Wardaniati, I., 2016, Gambaran Terapi Kombinasi Ranitidin Dengan Sukralfat Dan Ranitidin Dengan Antasida Dalam Pengobatan Gastritis Di Smf Penyakit Dalam Rumah Sakit Umum Daerah (Rsud) Ahmad Mochtar Bukittinggi, Jurnal Farmasi Higea, Vol. 8 No. 1. 